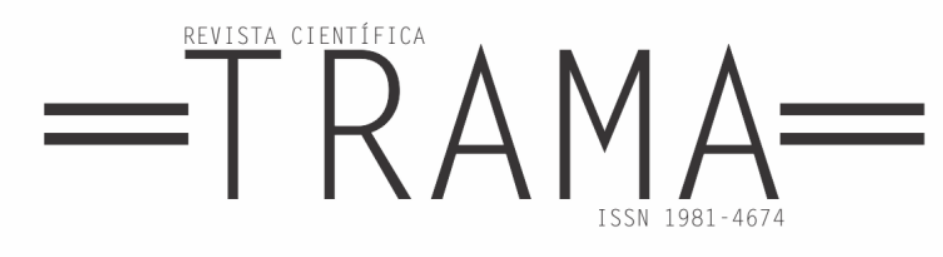

\title{
Aplicativos como ferramenta mediadora no EN- SINO-APRENDIZAGEM DA LÍNGUA ALEMÃ NO BRASIL: EIN PLUS OU EIN MINUS? ${ }^{1}$
}

\author{
Adriana Cristiane SCHLENKER ${ }^{2}$
}

Resumo: O trabalho em escolas que oferecem a Lingua Alemã no Brasil levantou questões referentes ao uso da Internet e de telefones móveis para o ensinoaprendizagem da língua. Devido ao rápido crescimento nas ofertas de aplicativos que visam não somente possibilitar, mas também facilitar a aprendizagem do idioma, questiona-se a eficácia desses aplicativos, os valores agregados a essas mídias e, por fim, o estudo colaborativo por meio dessa ferramenta. Sob esta perspectiva, intencionamos fomentar a reflexão a respeito do uso dos aplicativos, da didática aplicada por eles e as possibilidades dentro e fora de sala de aula, além de fazer uma revisão bibliográfica neste contexto.

Palavras-chave: Novas mídias, língua alemã, ensino-aprendizagem, autonomia.

\begin{abstract}
The work in schools offering German Language in Brazil raised issues relating to the use of the Internet and mobile phones for the teaching and learning of the language. Due to the rapid growth in application offerings that aim to not only allow, but also to facilitate learning of the language, questions the effectiveness of these applications, the value added to these media and, finally, the collaborative study through this tool is questioned. From this perspective, we intend to encourage reflection on the use of the applications, on the didactics applied by them and the possibilities inside and outside of the classroom, as well as to make a bibliographical review in this context.
\end{abstract}

Keywords: German as Foreign Language, Learning-Teaching, Autonomy.

Recebido em 14-09-2017

Aceito em 06-11-2017

\footnotetext{
${ }^{1}$ Tradução neste contexto: um ganho ou uma perda.

${ }^{2}$ Colégio Bom Jesus, CELIN (UFPR) e CLIE(UTFPR); Departamento de Letras Alemão, área de Ensino de Língua Estrangeira e Novas Tecnologias no Ensino.
} 




\section{Introdução}

Os termos Ambientes Virtuais de Aprendizagem e Processos Pedagógicos são atualmente recorrentes, porém ainda necessitam ser discutidos e pesquisados para que se estabeleçam parâmetros referentes ao ensino-aprendizagem da Língua Estrangeira Alemã (LE) no Brasil. É relevante salientar que o foco nesta proposta está na abordagem do uso de Aplicativos (Apps) e não no uso da rede em si, como no trabalho de exercícios online, sejam eles sincrônicos ou assincrônicos.

Neste contexto, pretendemos desenvolver uma discussão teórica e bibliográfica, incentivar a reflexão e a discussão entre os colegas de ensino a respeito do uso das novas mídias em ambientes virtuais, bem como realizar uma revisão bibliográfica. Atualmente, dispomos de um número significativo de trabalhos relacionados ao uso midiático no ensino-aprendizagem de uma Língua Estrangeira (LE). Porém, a discussão a respeito da LE alemã em âmbito nacional pode ser ainda ampliada.

O aporte teórico tem como referência os autores Funk, Tschirner e Koenig (2000) que abordam o ensinoaprendizagem do idioma por meio da internet e de seus recursos em sala de aula. A proposta visa um diálogo sobre a forma de avaliação e a análise de processos de ensino-aprendizagem, bem como o ganho intercultural $\mathrm{e} a$ autonomia dos alunos. Quanto à metodologia e didática da LE alemã, nos pautamos nas considerações de Funk (2010) e Bohunovsky (2011). Os autores procuram trabalhar com as ferramentas e as abordagens de ensino do idioma fora do meio onde este é falado. Oxford (2003) tem como foco pesquisas relacionadas às estratégias de ensino e aprendizagem de uma LE. Essas estratégias visam estabelecer e orientar os alunos sobre as diferentes formas de estudarem.

\section{Ambiente virtual}

Segundo Oxford (2003), aprender um idioma como segunda língua é aprendê-lo no local em que este idioma é a comunicação diária entre os demais, onde existe abundante motivação linguística. Enquanto aprender uma língua estrangeira é aprender um idioma em meio onde a comunicação não se dá no idioma que se estuda e, portanto, a motivação de interação é restrita. Diante deste contexto, é de vital importância que o aluno crie uma forma de manter contato com o idioma fora de sala de aula. Breindl (1997) afirma ser a comunicação por meio da internet, no ensino da LE, a grande dimensão promissora no ensino.

É sabido que os professores de uma LE lidam diariamente com as implicações culturais, linguísticas, de tradução, interpretativas, gramaticais e comunicativas para trabalhar entre os alunos a apropriação do idioma alvo. Ao utilizar as diversas formas de linguagem, o aluno passa a internalizar a estrutura da LE. Essa internalização é desenvolvida pela apropriação, que pode ser vista como uma "reconstrução feita pelos sujeitos das ferramentas psicológicas em seu desenvolvimento histórico", segundo Cubero e Luque (2004, p.98). Para esses autores, o ser humano se apropria das referências da cultura humana à medida que cria relações com outros indivíduos. Desta maneira, os seres humanos além de se adaptarem aos fenômenos que os cercam, também os tomam como seus, pois deles se apropriam.

Desta maneira, o ambiente virtual apresenta vantagens para a apropriação da língua estrangeira Alemã no Brasil, 


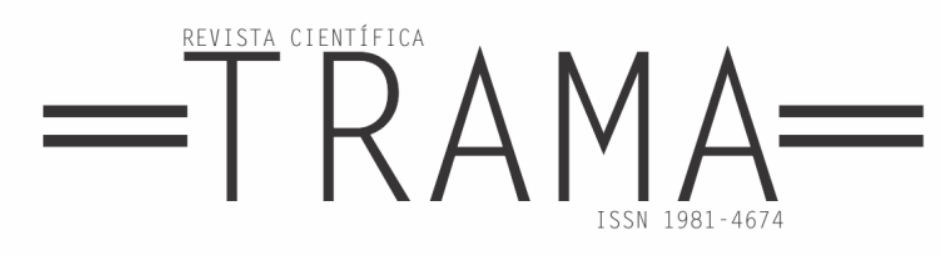

pois se dá por meio do acesso fácil e rápido a material autêntico disponível na rede. Breindl (1997) afirma ser possível minimizar as dificuldades naturais na aquisição da LE. O aluno pode, por exemplo, pesquisar particularidades referentes ao idioma, aos hábitos e costumes, ou seja, à cultura entre os habitantes dos diferentes países onde se tem a língua Alemã como língua materna, como na Áustria, Alemanha e Suíça. ${ }^{3}$ Vale mencionar que o vocábulo cultural é aqui pensado a partir do termo inglês Culture "tomado em seu amplo sentido etnográfico é este todo complexo que inclui conhecimentos, crenças, arte, moral, leis, costumes ou qualquer outra capacidade ou hábitos adquiridos pelo homem como membro de uma sociedade", por Edward Tylor (18321918) citado por Laraia (2004, p.25).

Nesse contexto, é relevante mencionar o trabalho em sala de aula para a sensibilização do aluno no que concerne às questões culturais envolvidas na aquisição do novo idioma. Um dos termos utilizados em alemão para significar esse processo é Landeskunde. Altmayer (2006) define o termo como o conjunto cultural, histórico, geográfico e político de um país. De acordo com Edgar Morin (2000), o conhecimento não reflete a realidade, ele é uma tradução e uma reconstrução dessa realidade. A partir dessa afirmação, podemos dizer que aprender um novo idioma é aprender a reconstruir uma nova realidade e que os ambientes virtuais possibilitam uma aproximação contextual da língua estudada. Para ilustrar a afirmação, cito a questão do clima, tema este que é encontrado em praticamente todos os livros didáticos. Questões como o frio e a neve no inverno da Alemanha

\footnotetext{
${ }^{3}$ DACH-LÄNDER: composto pelos países Alemanha, Áustria e Suíça, formando assim os países falantes da língua alemã na Europa.
}

constituem um cenário que instiga mudanças não somente na paisagem, mas também no comportamento dos moradores do país.

A partir desta acessibilidade, o aluno dispõe de informações que permitem desenvolver seu próprio ponto de vista em relação à interculturalidade, os afastamentos e as aproximações de "seu" mundo em relação ao outro.

\section{Problemática}

A Era Digital já está consolidada entre as novas gerações. Após passar por diferentes etapas evolutivas e diversas adaptações sociais, o uso de computadores e aparelhos móveis é realidade na maioria das escolas. No entanto, segundo Marques (2006, p.16) estas considerações implicam em um contínuo repensar sobre o avanço tecnológico por parte dos professores e das escolas. É necessária uma nova abordagem educacional para assegurar um processo de integração dos Apps em meio escolar.

Em relação às escolas, dois pontos devem ser levados em consideração: as limitações econômicas das escolas e dos alunos, bem como da localização geográfica. Locais distantes, muitas vezes, possuem acesso restrito à rede dificultando, assim, o trabalho com os Apps. Outro fator está relacionado ao conhecimento e ao envolvimento do professor com as novas tecnologias. Paiva (2001, p.114) constata que em relação ao ensino-aprendizagem de uma LE "O bom professor não é mais o que tudo sabe, mas aquele que sabe promover ambientes que propiciem o desenvolvimento da autonomia do aprendiz e que os desafia a 




aprender com o(s) outro(s), diante das oportunidades de interação e de colaboração". Marques (2006) atribui este conhecimento ao termo competência midiática, que se refere à maneira de se lidar com a tecnologia de forma eficiente. Em alemão, o termo similar é Medienkompetenz segundo Grießhaber (2004). A abrangência terminológica em relação ao uso dos meios de comunicação como a internet, os telefones, meios digitais e interativos, os telemóveis, smartphones, ipods e TV a cabo é denominada ambientes virtuais de aprendizagem e é equivalente ao termo tecnologias de informação e comunicação (TIC). Neste contexto, Funk (2000, p.13) aborda o termo Neue Medien com o mesmo significado acima mencionado e que, com o passar do tempo, este se tornou sinônimo para o termo internacional Informationstechnologie-Medien (IT).

É importante salientar que neste trabalho, as atividades oferecidas em rede não são o tema principal. Essa ferramenta já se consolidou entre as diversas editoras de livros didáticos, iniciativas privadas ou mesmo nas universidades e centros de idiomas. A atenção aqui é para o uso dos Apps, pois os ambientes virtuais de aprendizagem ganham destaque com a chegada dos aparelhos móveis. Estes são constituídos por um sistema operacional Android, Windows, IOS, entre outros, que permitem, a partir da conexão de Internet, o uso irrestrito tanto das atividades em rede, como dos Apps.

A oferta de aplicativos é grande e abordam diferentes temas para que o aluno possa desenvolver o aprendizado do idioma. Os Apps oferecem exercícios para treinar a conjugação de verbos, as declinações, o treino de vocabulário e de gênero das palavras, expressões idiomáticas, entre outros. Muito conhecidas e utilizadas são as mídias sociais facebook, instagram, twitter, que estão presentes na vida tanto dos alunos, como dos adultos. Porém, as mídias sociais não são o foco deste trabalho.

Contudo, o avanço tecnológico implica em uma avaliação crítica a respeito da utilização de Apps para a efetiva aprendizagem e ensino da LE dentro e fora de sala de aula. Durante o uso dos aplicativos em sala de aula, foi inevitável o questionamento a respeito de sua efetividade. A utilização dos Apps poderia dar suporte ao aprendizado do idioma e também estimulá-lo? Seria viável um uso autônomo desses Apps fora da sala de aula, não sendo parte de um projeto orientado pelo professor? A utilização de um aplicativo para treino de vocabulário pode realmente ajudar neste ganho? A atividade junto a esses Apps estaria abrangendo que tipo de memória - curta, longa, declarativa, não declarativa? Por fim, não seria a aprendizagem colaborativa a melhor maneira de explorar essa nova ferramenta de maneira mais efetiva? A forma colaborativa, segundo Figueiredo (2006), é a situação e o momento em que duas ou mais pessoas tentam produzir, aprender algo em conjunto. Para Donato e McCormick (1994), mesmo quando os estudantes têm a mesma proficiência no idioma, há uma troca nos papéis, ora um ajuda, ora o outro. Essas questões serão abordadas no decorrer deste trabalho.

\section{Pesquisas}

Atualmente, dispomos de um número significativo de trabalhos relacionados ao uso midiático no ensinoaprendizagem de uma língua estrangeira, porém a discussão referente ao ensinoaprendizagem da LE alemã em âmbito nacional pode ser ainda ampliada. Os idiomas que se destacam nas pesquisas são o inglês e o espanhol, muitas vezes obrigatórios nas escolas e largamente procurados em escolas de idiomas. Ao se 


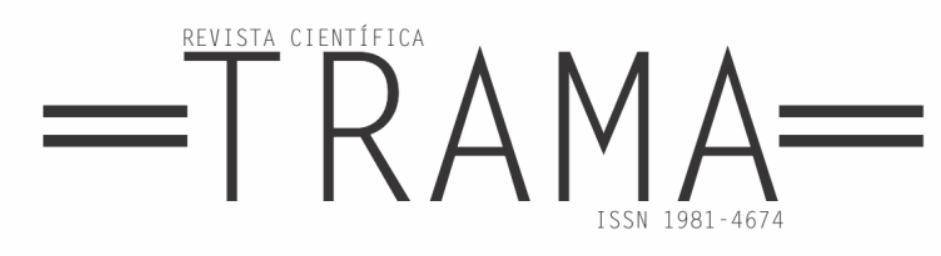

pesquisar no Google, encontramos diversas teses, pesquisas e artigos que abordam os processos pedagógicos e o ensino-aprendizagem do idioma em ambientes virtuais, os quais apresentam resultados positivos e motivadores. Marson e dos Santos (2015, p.1) em seus questionamentos e pesquisas, constatam "que os ambientes virtuais de aprendizagem possibilitam gerar práticas educativas com ganhos para o ensinoaprendizagem".

Giselda dos Santos Costa (2013) investiga a interação entre o aluno e o celular no desenvolvimento das habilidades linguísticas no ensinoaprendizagem da Língua Inglesa Estrangeira e conclui (2013, p.9) "que o uso do celular no ensino-aprendizagem de Línguas proporciona uma flexibilidade diferente, produtiva para o aprendiz adquirir saberes, habilidades e conhecimentos, quase impossível de ocorrer em um ambiente de ensino tradicional". Colognese e Rodrigues (2016) visam desenvolver uma análise das possibilidades oferecidas pela tecnologia da informação no ensinoaprendizagem de Línguas Estrangeiras e a viabilidade de utilizar as novas ferramentas no ambiente investigativopedagógico com base nos fundamentos da teoria dos gêneros do discurso proposto por Bakhtin. As TICs são utilizadas para trabalhar a Língua Inglesa em escolas públicas. Vale destacar também o artigo de Marques-Schäfer (2015), voltado à pesquisa da formação e o desenvolvimento profissional de professores de línguas estrangeiras em relação à Competência Midiática e às Tecnologias Móveis. Ainda que haja uma abrangência em relação aos professores de língua estrangeira de modo geral, ela é professora adjunta de alemão na UERJ.
Rozenfeld e Pinto (2009) apresentam em seu artigo o desenvolvimento de um curso on-line voltado para a formação continuada de professores de alemão.

[...] a fim de que esses profissionais pudessem não apenas buscar novos caminhos de desenvolvimento de suas competências para aprimoramento profissional em uma sociedade em transformação, mas também para maior familiarização com o uso das NTICs e a promoção de interação com outros profissionais da área (p.154).

As autoras apresentam os preceitos teóricos que deram suporte à concepção do curso e abordam dentro deste contexto os "preceitos de abordagem comunicativa e do ensino intercultural de línguas" (p.155), pois como o próprio título do artigo indica, há uma perspectiva na "aproximação de culturas a distância." Essa abordagem é de grande interesse para as discussões feitas junto ao uso dos Apps e o ensino da LE alemã. Também não deixamos de buscar as informações básicas das diretrizes curriculares da educação básica da língua estrangeira moderna (2008), ${ }^{4}$ que nos orienta a respeito dos parâmetros vinculados às línguas estrangeiras no ensino.

\section{Valores atribuídos}

Visto os resultados positivos no uso de tais ferramentas, fica a questão do valor atribuído a esses recursos. O termo em alemão Mehrwert, aqui traduzido como valor atribuido, tem justamente o propósito de determinar a valoração do uso midiático no ensino-aprendizagem de

\footnotetext{
${ }^{4}$ Disponível em: <http://www.educadores.diaadia.pr.gov.br/arquivos/File/diretri-

zes/dce_lem.pdf>. Acesso em: 12 set. 2017.
} 


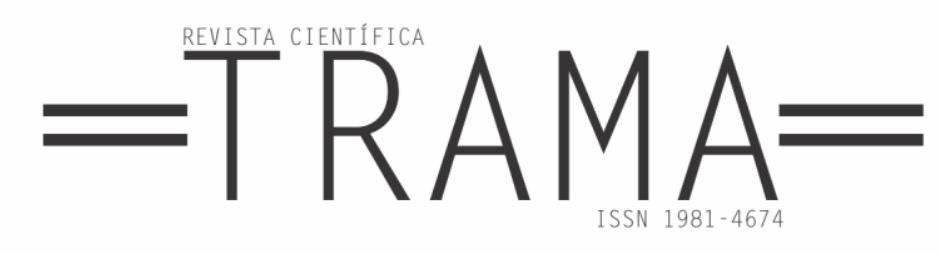

uma LE. Hermann Funk afirma que os valores atribuídos ao que concerne ao uso da Internet, consistem em determiná-los pelo reconhecimento e uso destes cinco campos de atividade: Treino, Comunicação, Cognição, Informação, Trabalho textual (2000, p. 14). Ou seja, abordar as diferentes técnicas e campos de aprendizagem para o desenvolvimento do idioma. Michael Kerres (2004, p.18) por sua vez, apresenta uma argumentação mais neutra a respeito do valor agregado ao uso das mídias, em que o importante é estabelecer e reconhecer uma função para esse uso. Ele afirma que o valor atribuído se dará pelo reconhecimento delas dentro do processo de aprendizagem:

O valor da didática de uma mídia não pode estar atrelado prioritariamente a características da mídia ou de seus meios (sejam elas de conteúdo, metodológicos ou qualquer forma de construção), mas sim somente na interdependência na qual a mídia encontra uma utilização.

Esta interdependência é o ponto que asseguraria um bom trabalho autônomo dos alunos ao se valerem dos Apps para treinar e desenvolver o aprendizado do idioma alemão fora da sala de aula. Porém, como fomentar essa correlação entre aluno e aplicativo, quando muitas vezes não há uma motivação para troca? $\mathrm{Na}$ Educação Virtual é a comunicação e a interatividade que determinam o diferencial pedagógico. Em Azevedo (2002, p.2):

[...] a origem desta dificuldade reside numa visão limitada do que é a Internet e do que são as novas tecnologias da informação e da comunicação. Predomina o aspecto "informa-

\footnotetext{
${ }^{5} \mathrm{O}$ congresso contou com a presença de mais de 60 países e mais de 1000 inscritos, sendo o maior
}

ção" sobre a "comunicação" na percepção de muitos. Enxerga-se muito mais as possibilidades de distribuição e organização da informação que as possibilidades de comunicação mediada por computador, especialmente de interação coletiva.

\section{$\mathbf{E}_{\text {stratégias }}$}

É possível que o uso de Apps traga apenas o contexto informação ao invés de oferecer uma forma de comunicação com outros usuários ou entre o App e o usuário. Alguns Apps apresentam jogos interativos com a finalidade de promover a comunicação e a apropriação de vocabulário. É visto que essa interação serve como um meio motivador para que o usuário, o aluno, continue desenvolvendo seus processos de aprendizagem ao passar pelos diferentes níveis de exercícios propostos. Entretanto, essa interação deve promover evolução no aprendizado e superação de conhecimento, caso contrário, corre-se o risco de o usuário, limitado a uma gama restrita de palavras e repetições, perder a motivação no processo e abandonar o App.

Diante desta situação, pode se dizer válida a proposta de utilização dos Apps como trabalho colaborativo entre os alunos. Em ocasião do XVI Congresso Internacional de Professores de Alemão (XVIa Internationale Tagung der Deutschlehrerinnen und Deutschlehrer), em Fribourg, Suíça, foram apresentados trabalhos desenvolvidos em diversos países na área do ensino-aprendizagem de Alemão, como LE e o uso das novas mídias. ${ }^{5}$ Diferentes instituições, níveis de conhecimento da Língua Alemã e diferentes objetivos de trabalho

congresso realizado na área do idioma Alemão. https://www.idt-2017.ch/. Acesso em 20 out. 2017. 


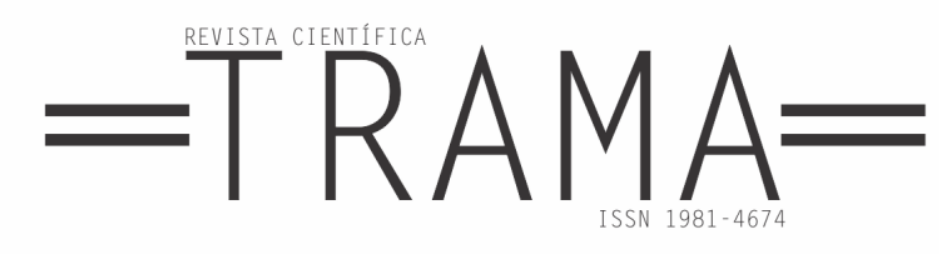

marcaram a diversificação de abordagens no ensino-aprendizagem. Esses trabalhos chamaram a atenção para o caráter colaborativo das atividades apresentadas. Diante desse contexto, vê-se uma validação para o uso no ensino-aprendizagem da LE sob a forma colaborativa.

Neste ponto, também é válido salientar que cada aluno apresenta uma característica diferente para desenvolver a aprendizagem de um novo idioma. Neste sentido, destacam-se as questões estratégicas de aprendizagem, estas que estão ligadas ao perfil de cada aluno, e que nem sempre são desenvolvidas por ele de forma consciente. Para utilizar estratégias é preciso que o aluno saiba reconhecê-las, podendo assim escolher as mais compatíveis com seu estilo. Conforme Oxford (2003), aprendendo estilos é a forma de aproximação generalizada utilizada pelo aluno para com a língua de estudo, por exemplo: de forma global, analítica, auditiva, visual, entre outros. Os estilos mais significativos compreendem "preferências sensoriais, tipos de personalidade, grau desejado de conhecimento e diferenças biológicas (2003, p. 360)". ${ }^{6}$ As preferências sensoriais podem ser divididas em 4 áreas principais: visual, auditivo, tátil e sinestésico. Tendo em vista essas variedades básicas no perfil dos nossos estudantes de LE, é possível tentar uma conexão entre esses perfis e o uso dos ambientes virtuais para ajudar a otimizar os estudos e tentar aumentar a valoração dessa utilização, pelo aluno. Oxford (1990, p.8) “[...] aprendendo estratégias são ações específicas tomadas pelo aluno para fazer com que o estudo se torne mais

\footnotetext{
${ }^{6}$ No original: "Sensory preferences, personality types, desired degree of generality, and biological differences". Tradução minha.

${ }^{7}$ No original: "Language learning strategies are specific actions taken by the learner to make learning eaysier, faster, more enjoyable, more
}

fácil, rápido, prazeroso, efetivo, autônomo e adaptável a novas situações"?

Ainda no âmbito das estratégias, é importante salientar a questão da memória no processo de aprendizagem de uma LE. A memória, como anteriormente questionada em relação aos Apps, é aqui entendida através da perspectiva de Venturini (2008 p.36) "pela capacidade de reter e evocar informação de natureza perceptual e conceitual". Três tipos de memória são propostos: a sensorial, a qual retém por milésimos de segundo a informação, a de curto prazo, a capacidade das pessoas de reter e repetir, e a de longo prazo, que é a capacidade de retenção indefinida, experiências e saberes armazenados ao longo da vida. ${ }^{8}$ Esta também é dividida em memória semântica e episódica. A memória semântica "armazena os saberes culturais, todos os conceitos aprendidos ao longo de nossa vida, presentes no vocabulário adquirido à medida que nos adentramos na cultura e aprendemos nossa língua (Venturini 2008, p.36)". A episódica "contém nossas recordações, as representações verbais ou sensoriais de tudo vivido por nós em momentos e lugares determinados". O conteúdo desta memória está mais ligado ao contexto originário na experiência. Ainda que as estratégias de aprendizagem não sejam o foco desta proposta, elas são relevantes para o estabelecimento de um paralelo nas atividades que adotam a rede ou os aplicativos como recurso didático.

selfdirected, more effectible, and more transferrable to new situations".

8 Ávalos, M. V. de. (org). Comprensión lectora: dificuldades estratégicas em resolución de preguntas inferenciales. Buenos Aires: Ediciones Colihue S.R.L. [s.d.]. 


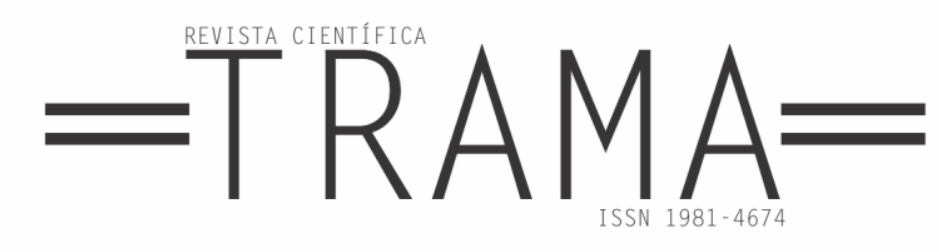

\section{Considerações finais}

\begin{abstract}
A partir destas considerações e a prática pedagógica no ensinoaprendizagem com tecnologias educacionais, se delineia uma proposta real de pesquisa e desenvolvimento desta mídia dentro do âmbito educacional. É interessante salientar que a partir de um trabalho em ambiente colaborativo, o aluno possa assumir uma postura mais ativa do que passiva, ou seja, mais autônomo em relação à sua aprendizagem. Através do ambiente em sala de aula com aplicativo, a falta de interação do App com cada aluno, pode ser compensada na interação entre os alunos. Este recurso inovador no ensino da LE alemã, desperta o encantamento por parte do aluno, porém não garante por si só a aprendizagem e autonomia nos estudos.
\end{abstract}

\section{$\mathbf{R}_{\text {eferências }}$}

ALTMAYER, Claus: Landeskunde als Kulturwissenschaft. Ein Forschungsprogramm. In: Jahrbuch Deutsch als Fremdsprache 32 (2006), S. 181-199.

BOHUNOVSKY, R. Ensinar Alemão no Brasil. Contextos e Conteúdos. Editora UFPR, 2011.

BREINDL, EVA. (1999): DaF goes Internet! Neue Entwicklungen in Deutsch als Fremdsprache. In: Deutsche Sprache 4/1997, S. 289-342, cap.3.1.1. Disponível em: $\quad<\quad$ http://pub.idsmannheim.de/abgeschlossen/orbis/daf/dafk ap3.html> Acesso em: 27 out. 2017.

COLOGNESE, R.M.; RODRIGUE, W. Tecnologia como instrumento de ensino aprendizagem em língua estrangeira. Disponível em: http://www.gestaoescolar.diaadia.pr.gov.br/ arquivos/File/producoes pde/artigo rose $\mathrm{m}$ ari_colognese.pdf. Acesso em: 23 ago. 2017.
COSTA, G. S. Mobile learning: explorando potencialidades com o uso do celular no ensino - aprendizagem de língua inglesa como língua estrangeira com alunos da escola pública. Disponível em: <http://www.repositorio.ufpe.br/bitstream/handle/123456789/11333/TESE\%20Giselda\%20dos\%20Santos\%20Costa.pdf?sequence $=1 \&$ isAllowed $=\mathrm{y}>$ Acesso em: 03 set. 2017.

CUBERO, R., \& LUQUE, A. (2004). Desenvolvimento, educação e educação escolar: a teoria sociocultural do desenvolvimento e da aprendizagem. In C. Coll, J. Palácios \& A. Marchesi (Eds.), Desenvolvimento Psicológico e Educação. Psicologia da Educação (pp. 94-106). Porto Alegre: Artes Médicas.

DONATO, R.; McCORMICK, D. A sociocultural perspective on language learning Learning Strategies: The Role of Mediation. The Modern Language Journal, W. 1994, v. 78, n. 4, Winter 1994, 417-571 p.

FUNK, H. Methodische Konzepte für den DaF-Unterricht - Grundlagen, Prinzipien, Lernfelder und Modelle. In: Krumm, H.; Fandrych, C.; Hufeisen, B.; Riemer, C. Deutsch als Fremd- und Zweitsprache. Ein internationales Handbuch. Berlin, New York: Mouton de Gruyter, 2001. P. 940-952. FIGUEIREDO, F. J. A aprendizagem colaborativa de línguas: algumas considerações conceituais e terminológicas. In: FIGUEIREDO, Francisco José Quaresma de. A aprendizagem colaborativa de línguas. Goiânia, Editora UFG, 2006. p. 11 - 45.

GU, P. Y. Learning strategies:prototypical core an dimensions of variation. Editora: Aucklan, N.Z., AIS St Helens. Centre for Research in International Education, 2005 .

GRIESSHABER, W. Medienkompetenz und Computereinsatz. Auszug aus dem Zwischenbericht der wissenschaftlichen Begleitung. Sprachenzentrum der WWU Münster, März 2004.

KERRES, M. Allgemeine Didaktik im Wandel. in: Dieckmann, B.\& P. Stadtfeld Bad Heibrunn: Klinhardt Verlag, 2004. Disponível em: http://d-nb.info/974017566/04. Último acesso em: 14 set. 2017.

KISSNER, H. Anforderungen an eine Lernumgebungsdesign bei der Entwicklung und 


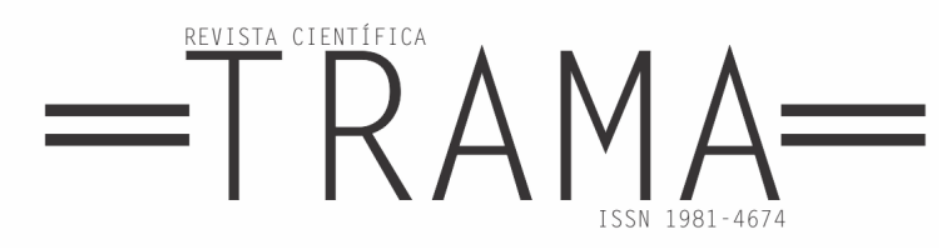

Nutzung Neuer Medien. In: Girmes, R. Lerdesign und Neue Medien: Analyse und Konstruktion. Münster. Waxmann, 1999. p.59-83.

KOLL, M. de O. Vygotsky: Aprendizado e desenvolvimento: um processo sócio-histórico. São Paulo: Scipione, 2010.

LARAIA, Roque de Barros. Cultura, um conceito antropológico. Rio de Janeiro: Jorge Zahar Ed., 2004.

MARCHESI, Á.; PALACIOS, J. Desenvolvimento psicológico e educação. 2. ed. Porto Alegre. Artmed, 2004.

MARQUES, G.O. Tecnologia e internet no ensino de língua estrangeira: avaliação discursiva de professores e alunos.162 f. Tese de mestrado. Pontifícia Universidade Católica do Rio de Janeiro, RJ, 2006.

MARSON, I.; SANTOS, A. A Formação continuada de docentes de língua inglesa: Contribuições didático-pedagógicas do uso de ambientes virtuais de aprendizagem, 2015. Disponível em: http://www.epublicacoes.uerj.br/ojs/index.php/emosaicos/article/view/17119/12588. Acesso em: 27 out. 2016.

MORIN, E. Os sete saberes necessários à educação do futuro. Cortez Editora, 2006.

NUNAN, D. Research Methods in Language Learning. Cambridge University Press, 1992.

OXFORD, R. Language learning styles and strategies. Berlin, Walter de Gruyter, 2003.

PAIVA, V. L. M. O. A www e o ensino de inglês. Revista Brasileira de Linguística Aplicada.v.1, n.1, p. 93-116, 2001.

PRETI, O. A aventura de ser estudante: um guia metodológico. 4.ed. rev. Cuiabá, EDUFMT, 2000.

ROZENFELD, Cibele Cecílio de Faria; PINTO, Ana Maria de Senzi Moraes. Deutschkurs Kulturenannäherung: uma proposta para a formação continuada on-line de professores, p. 153-173. In: Soto, Ucy; Mayrink, Mônica Ferreira; Gregolin, Isadora Valencise (orgs.) Linguagem, educação e virtualidade. São Paulo: Editora UNESP, 2009.

SCHÄFER, G. M. Competência Midiática e Tecnologias Móveis: Desafios e Perspectivas para a Formação de Professores de Línguas Estrangeiras. In: $1^{\circ}$ Congresso da Associação Brasileira de Estudos Germanísticos (ABEG) 09-11 de novembro 2015 - USP São Paulo. Disponível em: http://germanistik-brasil.org.br/wpcontent/uploads/2016/03/GabrielaMarques-Scha\%CC\%88fer.pdf. Acesso em 29 out.2016.

SCHIER, C. Interkulturelles und interdisziplinäres Lernen durch universale Themen. Zeit als Kulturthema. In: Renate A.; Schulz \& Tschirner, eds. 2008. Communicating across Borders: Developing Intercultural Competence in German as a Foreign Language. München: Iudicium, 126-146.

TSCHIRNER, E Kommunikation und Spracherwerb per Computer. Blick auf einige Forschungsergebnisse. Fremdsprache Deutsch, 1999. v. 21, n. 2, 54-58 p. .; HENRICI, G.; ZÖFGEN, E. Zur Einführung in den Themenschwerpunkt. Neue Medien im Fremdsprachenunterricht: Fremdsprachen Lehren und Lernen. Themenschwerpunkt: Neue Medien im Fremdsprachenunterricht. Tübingen: Gunter Narr Verlag, 1999. ., FUNK, H., \& KOENIG, M.

Schnittstellen: Lehrwerke zwischen alten und neuen Medien. Berlin: Cornelsen, 2000. VENTURI, Maria Alice. Tópicos de aquisição e ensino de língua estrangeira. São Paulo: Humanitas, 2008.

Colón en las novelas de Carpentier y Posse. Del@ Investigación, Guadalajara. nov. 2014. Disponível em: http://www.jcortazar.udg.mx/dela/invmarco.pdf. Acesso em: 30 nov. 2014. 